\title{
DIASONE IN THE TREATMENT OF LEPROSY.
}

E. Muir.

In 1944-45 I had an opportunity of testing the effect of diasone in the treatment of some 83 patients in Trinidad, B.W. Indies. Untortunately on my leaving Trinidad in February, 1945, I had to discontinue the test, but a preliminary report was published. (Muir, 1944.) In this the opinion was expressed that without doubt diasone is of definite value in the treatment of leprosy especially in clearing up febrile and inflammatory conditions associated with lepra reaction. The question was raised as to whether diasone has a direct effect in destroying or preventing the growth of the leprosy tacillus, or whether improvement is attributable only to the destruction of accompanying pyogenic organisms which had complicated the majority of cases in the trials. To determine this a few patients in the early stage of the lepromatous type and not ret affected by septic complications, had been included. These had shown improvement but there had not been time to determine whether the treatment would lead to complete elimination of 'epra bacilli.

The results obtained in the first trials were considered encouraging and, though it was still too soon to make any definite statement as to the extent to which this drug would be of use, there was reason to believe that a distinct step forward had been made in the treatment of leprosy.

Atter returning to England I had, through the kindness of the Department of Medicine, Abbott Laboratories, an opportunity of arranging for supplies of diasone to be sent for further trials to two suitable centres in India and one in West Africa, and also of making trials myself in twelve patients in this country. The 
following brief report gives the details of treatment and the results so far obtained in these twelve patients, most of whom have now been taking diasone for over a year.

In the Trinidad trials the majority. received the drug intravenously and some oraliy, but there was not time to determine which of these methods was preferable. In the present test the oral method has been used alone.

The few patients available for trial in this country did not allow of selection of cases. Of the twelve, ten were fairly advanced lepromatous cases, and two may be described as intermediate, although at the commencement of treatment their bacteriological examinations gave strongly positive results.

\section{METHOD OF ADMINISTRATION.}

Diasone is described as the di-sodium formaldehyde sulphoxylate derivative of diaminodiphenyl sulphone.

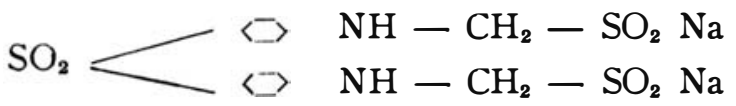

It is supplied as a white powder and is usually made up in $\frac{1}{3}$ gram capsules. Previous clinical observations in tuberculosis have shown that in that disease the most suitable dose is 1 gram per day, although patients have tolerated daily doses of 5-7 grams for periods up to a maximum of 6 weeks. Two grams a day has been found to cause anaemia unless iron, along with liver or yeast, is administered.

Relying on the previous experience referred to, we adopted the plan of giving one capsule on alternate days three times a week, say on Mondays, Wednesdays and Fridays and, provided there are no contra-indications, increased the dose on each of these three days by one capsule every week until 6 capsules three times a week was reached in the sixth week. After this, provided the patient was doing well and there was no reason to the contrary, diasone was given in addition on Tuesdays, Thursdays and Saturdays, again beginning with one capsule on each day and increasing by one capsule each day up to six.

Thus, as is shown in the table, the patient reached the average dose of six capsules (approximately 2 grammes) a day six days a week. This is considered to be the maximum for a patient of 140 lbs. weight, but it may be increased or diminished according to the weight. After the maximum dose is reached each three weeks' period of treatment is followed by a week's rest without diasone. 


\section{DOSAGE TABLE.}

\begin{tabular}{|c|c|c|c|c|c|c|c|c|c|}
\hline \multicolumn{4}{|c|}{ Week. } & Miom. & \multicolumn{4}{|c|}{ Number of Capsules. } & Sat. \\
\hline 1 & $\ldots$ & & & 1 & & 1 & & 1 & \\
\hline 2 & $\ldots$ & $\ldots$ & $\ldots$ & 2 & & 2 & & 2 & \\
\hline 3 & $\ldots$ & $\ldots$ & $\ldots$ & 3 & & 3 & & 3 & \\
\hline 4 & $\ldots$ & $\ldots$ & $\ldots$ & 4 & & 4 & & 4 & \\
\hline 5 & $\ldots$ & $\ldots$ & $\ldots$ & 5 & & 5 & & 5 & \\
\hline 6 & $\ldots$ & $\ldots$ & $\ldots$ & 6 & & 6 & & 6 & \\
\hline 7 & $\ldots$ & $\ldots$ & $\ldots$ & 6 & 1 & 6 & 1 & 6 & 1 \\
\hline 8 & $\ldots$ & $\ldots$ & $\ldots$ & 6 & 2 & 6 & 2 & 6 & 2 \\
\hline 9 & .... & $\ldots$ & $\ldots$ & 6 & 3 & 6 & 3 & 6 & 3 \\
\hline 10 & $\ldots$ & $\ldots$ & $\ldots$ & 6 & 4 & 6 & 4 & 6 & 4 \\
\hline 11 & $\ldots$ & .. & $\ldots$ & 6 & 5 & 6 & 5 & 6 & 5 \\
\hline 12 & $\ldots$ & $\ldots$ & $\ldots$ & 6 & 6 & 6 & 6 & 6 & 6 \\
\hline 13 & $\ldots$ & $\ldots$ & $\ldots$ & 0 & 0 & 0 & 0 & 0 & 0 \\
\hline 14 & .... & $\ldots$ & $\ldots$ & 6 & 6 & 6 & 6 & 6 & 6 \\
\hline 15 & $\ldots$ & $\ldots$ & $\ldots$ & 6 & 6 & 6 & 6 & 6 & 6 \\
\hline 16 & $\ldots$ & $\ldots$ & $\ldots$ & 6 & 6 & 6 & 6 & 6 & 6 \\
\hline 17 & $\ldots$ & $\ldots$ & ... & 0 & 0 & 0 & 0 & 0 & 0 \\
\hline
\end{tabular}

Contra-indications.

The danger signals or reasons for diminishing or temporarily discontinuing diasone treatment are lepra reaction and anaemia.

1. Lepra reaction. This shows itself by a rise of temperature, by the flaring up of existing clinical lesions or the appearance of new lesions. In the beginning of treatment diasone often has the effect of alleviating this condition where it already exists, and causes healing of ulcers, clearing up inflammatory eye and nose complications.

On the other hand; after the treatment has been begun a dose, however small, which for the moment is excessive, may provoke reaction, and this is an indication for diminishing or temporarily stopping diasone treatment until the reaction has subsided. Gradually the patient becomes able to tolerate larger doses and signs of reaction become less marked until they disappear entirely.

2. Anaemia. In many advancing cases of the lepromatous type the paticnt suffers from anaemia, especially in the tropics. Before beginning treatment it is well to make a thorough blood examination, with special attention to the haemoglobin percentage. If this be below 75 per cent the patient should be given full doses of iron for at least a week before diasone treatment begins, and this should be continued along with the diasone till the percentage rises to 80 per cent or more.

Like other sulphone and sulphonamide drugs diasone has a tendency at first to cause or increase anaemia, and it is well to 
make haemoglobin examinations once a week or fortnight during the early stages of the treatment. If the percentage in spite of iron continuis to fall or remains low, then diasone should be stopped or the dose diminished temporarily and iron pushed. Sometimes also liver extract is of marked value.

In most patients in whom there is an initial tendency towards anaemia, this gradually diminishes and, as the general condition improves the haemoglobin percentage rises and remains at a high level and larger doses of diasone are tolerated.

3. Other complications to be watched for are renal and cardiac disease, but in none of the cases treated have these complications given any trouble.

\section{TOLERANCE.}

Apparently the body gradually acquires tolerance to diasone as, once the maximum dose mentioned has been reached, it is generally possible to continue indefinitely, giving 12 grammes a week for three weeks a month, without further occurrence of the two adverse signs mentioned above. Instead of flaring up, as the lesions are apt to do at the beginning of treatment, they gradually tend to flatten out and disappear and the haemoglobin percentage, which often inclines to be low in the lepromatous type of leprosy and to become lower at the beginning of treatment, may reach a higher level than the original level once the treatment is well under way. Once this stage has been reached it is possible to continue treatment for an indefinite period with a far less degree of supervision.

There are probably two factors which account for this tolerance. In the literature supplied by Messrs. Abbott Laboratories it is mentioned that when diasone is administered over a period of time the blnod levels drop rapidly from what they are initially. "At a dosage level of 1 gram per day, the blood concentration ranges usually between 1.5 and $2 \mathrm{mg}$. per $100 \mathrm{cc}$. The blood concentration does not increase in proportion to an increased oral dose. A $100 \%$ increase in the daily oral dose will usually produce only a $10 \%$ to $20 \%$ increase in the diasone blood level. The diasone blood level begins to drop off in the majority of cases after a period of six to eight weeks therapy and continues to drop as the period of therapy extends, until there may be as little as $0.5 \mathrm{mg}$. or less per $100 \mathrm{cc}$. of blood." This wou'd explain to a large extent the absence of anaemia and of reactionary signs after the initial period of treatment.

The other factor which might be expected to affect the latter if not the former of these complications is the improvement 
of general health, the better appetite and ability to take more excrcise which commonly follow the initial period of treatment.

It is not claimed that the method of dosage used in this trial is the safest, most economical and most effective. The fact that the blood level does not increase proportionately when the daily dose is increased above 1 gram, and that during six or eight weeks' treatment the blood level gradually falls till it is only a third or a quarter of the previous level, suggest that there might be an advantage in lengthening the periods both of administration and of rëst. If the fall in blood level is due to lowering of the threshold of renal excretion, as suggested by the experimental work of Smith, Emmart and Stohlman (1943), it is important to find out what period of non-administration is necessary to restore the original threshold level. In three of our patients slight reactions followed the resumption of treatment after the period of rest, suggesting that a higher blood level had been reached resulting in this reaction. Careful experiments are called for to work out the safest and most effective dosage.

The following are reports of the twelve cases treated :-

Case 1. An L 3 case. Had been on hydnocarpus injections for several years. Both eyes were destroyed by leprosy. Diasone was begun on 20.8.45 and given three times a week, the first week 1 capsule to the dose, second week 2. After this it had to be stopped from 2nd to 12th September as there was a febrile reaction and nodules were coming out. On the 17 th of September the dosage was renewed, 2 capsules being given three times a week for one week, then 3 capsules three times a week for three weeks. The dosage was then gradually raised to 6 capsules three times a week. From 28.3.46 dosage was raised to 6 capsules six days a week for three weeks, followed by one week's rest. This, however, had to be reduced because of febrile attacks. With 6 capsules three times a week and 1 or 2 on the alternate days, the temperature remains normal, but it should soon be possible to reach the maximum amounts. Since the reaction teferred to there has been no further flare up of lesions but there is a slight reaction when treatment is resumed after a week's rest. The nodules have flattened out and the skin has become markedly thin and wrinkled. The patient is fecling considerably better. Bacterioscopy shows reduction of bacilli in the skin. In the nose the bacilli appear to be broken down and and very granular.

Case 2. An L 2-3 case. Had been on hydnocarpus treatment for several years. On this he had improved but had from time to time suffered reactions. He began diascne on 27.10 .45 with 1 capsule three times a week. The dose was gradually increased up to 6 capsules three times a week. On 28.3.46 the dosage was raised to 6 capsules six times a week for three weeks, followed by one week's rest. There is now considerable thinning of the skin. For a time very small nodules appeared and disappeared within a day or two, but these have now become less. The patient's general health has improved. His left eye, which was considerably involved, has almust entirely cleared up, leaving an irregular pupil but with considerable reaction to light and $6 / 18$ vision. The right eye which had begun to be involved has become normal, with regular fully reacting pupil and 6/6 vision. Bacterioscopy shows now only a few scattered bacilli in the skin; the nose shows large masses of bacilli but these are very granular and broken down.

Case 3. This patient, 7 years old, was first seen in the spring of 1945. There was considerable swelling of both ears and of the face, 
and ring-shaped asymetrical lesions of the buttocks and trunk. Bacilli were present in biopsy smears from the ear and ring patches in considerable numbers. There was some doubt in prognosis as the conditions resembled in certain respects both types of leprosy, and he could therefore be considered an indeterminate case. The general health was bad and the patient anaemic. He was put on iron, and with this and careful nursing his general lieaith improveri. Jiasone was begun on 9.8 .45 one capsule being given three times a week for two weeks, then 2 capsules three times a week for four weeks, and then a permanent dosage of 3 capsules three times a week was introduced. On 15.9 .45 very scanty bacilli were found. The thickening of the ears disappeared rapidly and the patches began to grow fainter. The patcles were painted with tricliloracetic acid and int:adermal injections of moogrol given. On 16.2.46 smears from the ear and butlock were negative, as lias been the case on subsequent examinations up to August, 1946. The patclies lave now almost entirely disappeared and the patient is in rolust health. To what extent this improvement is due to better general health and natura! causes, and how much is due to diasone, it is difficult to juclge. Unfartunately there was not an opportunity of doing the lepramin test before treatment. When it was done recently it was found to be moderately positive.

Case 4. An L 3 case of long duration. Blind. On 27.10 .45 he was given 200,000 units of penicillin. This was followed by a severe reaction and painful inflammation of the eyes and b:eaking down of ulcers. Within three weeks the ulcers had healed up again and the patient was feeling much ietter. He began diasone on 19.11 .45 and his condition has continued to improve. Formerly let had repeated breaking down of the skin to form ulcers, and an inflammatory condition of the throat. These have now disappeared. He is taking 12 grammes of diasone weekly without ill effects. The bacteriological examination shows now only 8 bacilli in 100 fields.

Case 5. An L 3 case of long duration. Blind. He had been on chaulmoogra treatment for many years. He began diasone on 20.8.45, the thrice weekly dosage being inc:ealsed every week from 1 up to 6 capsules. On 28.3.46 the administration of diasone was increased from three days a week to six. Ai first there was the appearing and fading of nodules. $\mathrm{He}$ scon began to feel much better than he lad before, and there is now a distinct flattening of the rassed skin lesions, many of which have been reduced to scars. Very slight reactions were noticed when treatment was resumed after a week's rest. Bacterioscopy shows only 5 bacilli in 14 fields in the skin and a few small clumps in the nose, a very considerable improvement from previous examinations.

Case 6. A bad $L 3$ case also with tuberculosis of the spine. Treatment with diasone in this case has had to be interrupted frequently because of the weakness of the patient and andaemia. She was given iron daily and anahaemin once a fortnight. Jiasone was gradually increased to six capsules three timess a week, and then to $6,3,6,3,6,3$. This patient had been on chaulmoogra for many years, but had got gradually worse. A remarkable thing is that after 9 months of diasone her lepromin test gave a double positive result one month after injecting 0.2 of Dharmendra's antigen. The test was done on two sites and both reacted. The nodule formed on the site of an apparently healed lesion, liquified and discharged. This patient is now remarkably well. At the beginning of treatment she had for long been bedridden, but is now able to walk actively about.

Case 7. An $\mathrm{L} 2$ case. Diffuse nodules of the hands. Began diasone on 15.10.45, the dcsage being gradually raised to 6 capsules three times a week, and on 28.3 .46 raised to 6 capsules six days a week. The patient also has high blocid pressure. Thick lepromatous patches and nodules of hands and knees have disappeared, or left scars. The eyes which were seriously involved, have become quiescent. The general health has improved. This patient also shows slight signs of reaction when treatment is resumed after a week's rest.

Case 8. This patient has been suffering for many years and was a severe L 3 case, with considerable ulceration of various parts of the body, 
especially the fingers. Before he began diasone he was very weak and could only walk a short distance. I liatsone was hegun on 10.8 .45 with 3 capsules six days a week, increasing by 1 capsule a day up to a maximum of 7 capsules. On 31.3.46 as there were signs of reaction, the administration was changed from 6 to 3 days a week. At first there were shortness of breath, digestive disturbances and other symptoms such as dizziness, frequent micturation and, on one occasion, palpitations. The pationt was put on iron begimning with small doses and gradually rising to 30 grains of ferrous carbonate daily. I)iasone treatment was interrupted on the 6th of September owing to marked dizziness, on the 20th of October due to indigestion and anaemia, and on January 5th, 1946, owing to indigestion and palpitations. The last of these, however, may have been due to an attack of influenza. There was three weeks' interruption of treatment in all. The dector now in charge of the case reports that "there is no doubt that the results of diasoine have been most spectacular. The nodules have been much absorbed. The general effect on the psychological side has been amazing, as he does not mind going out now nearly as much as he did. I ke pt him on a course of iron the whole time. It seems to keep his haemoglobin up to $80 \%$." In August, 1945, the patient could walk only about $1 \frac{1}{2}$ miles a day. From January, 1946 he has gradually increased the distance and cun now walk four miles a day. His eyesight has improved and there is no tendency to the recurrence of ulcers of the skin. The finger nails have improved, also the tendency to scaling, and the whole condition of the skin has improved.

Case 9. I have not myself seen this patient, but have treated him through corresponcience witli his own doctor. There were abundant bacilli in the nasal secretion and tiny ulcers on the hands, scalp and legs. Diasone treatment was begun on 14.1.46, the dose gradually rising to 5 capsules three times a week. The doctor reports that "at the outset 1 found abundant bacilli in the nasai secretion, in smears from tiny ulcers of the hands, scalp and legs, and in apparently normal skin of the lobe of the ear. Snears from nose and scalp ulcers were still positive on 12.2.46 and from the ulcer on the hand on 18.2.46, but yesterday, 15.4.46, all the ulcerations had healed, there was no nasal discharge, and from 2.4.46 onwards nasal smears have bcen negative for M. leprae. He looks and feels very much better, but he has parasthesia of the fingers still, though even this symptom is less than at the beginning of treatment. I found his haemoglobir to be fully $90 \%$ three weeks ago. $M_{y}$ impression is that diasone has done quite as well as moogrol and, as injecticn had become a real difficulty, oral treatment has heen a great boon and has given him encouragement which it would be hard to over estimate." Not having seen this case I am unable to determine definitely the type of disease, and consequently to what extent the improvement might have been due to diasone and to what extent to natural causes.

Casc 10. An L 3 case of long duration. He began diasone in the end of January, 1946. Has been on 6 capsules weekly for some months and is now gradually being raised to 12 grammes a week. Hb $90 \%$. This patient has very definitely improved. His eyes had been badly damaged by leprosy but under diasone became quiescent. It was thus possible recently to do an iridectomy which has considerably improved vision. Cutaneous nodules have flattened out and the skin infiltration became much less.

Case 11. An L 3 case of two years' known duration. Diffuse infiltration with several nodules and raised plaques. On diasone since June, 1946. It is still too soon yet to report on this case, but the doctor in whose charge is the treatment, reports that nodules and pigmentation have disappeared and the general condition of the patient has improved.

Case 12. This patient, an L 2-3 case, suffering from leprosy for over 13 years, was admitted to hospital in a bad condition suffering from cystitis and a purulent eye condition. Has been on diasone since May, 1946 and is now taking 12 grammes per week. The septic conditions have cleared up under appropriate treatment. As regards leprosy there is definite impovement, but to what extent this is due to diasone, and to what extent to the general betterment of health, it is difficult yet to say. 


\section{DISCUSSION.}

In all patients without exception there has been improvement, and in some marked improvement. Case No. 3 became bacteriologically negative and all other active signs have now been absent for some months, but to what extent this is due to diasone it is impossible to say.

One of the most delicate tests of improvement is the eye condition. In cases 2, 6, 7 and 10 gradual eye deterioration, which would have been expected in the usual course to lead soon to complete blindness, has bcen arrested and vision to a certain extent restored.

Cases 1, 2, 4, 5, 6, 8, and 10 had all been on chaulmoogra treatment for years but, in spitc of this, were gradually becoming worse. Under diasonc, either from the beginning or after a few weeks' or months' treatment, they have all made steady and definite improvement. One striking sign of improvement is the gradual cessation of febrile attacks and crops of nodules from which they had suffered for years. Also the steady improvement and maintenance of general health. What the final result in these cases will be it is still too soon to say.

In the former report referred to in the beginning of this paper the question was raised as to whether diasone has a direct effect in destroying or preventing the growth of the leprosy bacillus, or whether improvement is attributable only to the destruction of accompanying pyogenic organisms which haf complicated the majority of cases in the earlier trials. In the present cases septic complications have been practically absent, and there is thus clearer evidence that diasone has the power of clearing up, at least to a certain extent, uncomplicated lepromatous lesions in a great majority of cases. How far this process will continue and how it is brought about it is still too early to form any opinion.

During more than 27 years of experience of leprosy treatment and the trial of many drugs, the author has not seen any remedy for definite lepromatous cases of leprosy which has given such uniformly favourable results.

Whatever effective treatment is found for the lepromatous type of leprosy it is likely to be prolonged except when it is begun in the early stages of the disease. In highly endemic areas, such as those in India, China and Africa, there are large numbers of cases to be treated, and skilled staff is generally very limited in number. There are therefore three requirements to be met by any drug that is to be really effective :-

(1) It must be of sufficiently low toxity so that, at least after 
the early stages of treatment, it can be safely administered without elaborate tests requiring considerable time and skill, and can be tolcrated over a period sufficiently long.

(2) It should be easy to administer and capable of being given by mouth.

(3) It must be able to bring about steady improvement in the average case until the disease entirely disappears, and to prevent relapse.

(4) It should be easy to manufacture and therefore capable of being produced in sufficient quantity and at a low enough price, having reference to the poverty of the patients and of their countries.

Diasone appears to meet the first two and, at least to a certain extent, the third of these requirements. The majority of patients treated have been turned from gradually deteriorating into gradually improving cases, though it is still too soon to say more than this. Similar favourable results have been obtained with other drugs of the sulphone group, and there is reasonable hope that from this beginning advance will be made to drugs even more effective in the treatment of leprosy.

Regarding the fourth requirement, it is too soon yet to say if diasone can be produced in sufficient quantity and at a price low enough to make it available for the thousands of indigent patients in such countries as those mentioned. The initial expense in large scale manufacture is bound to be great, and it is difficult for private firms of manufacturing chemists to meet this expenditure when there is no assurance that their product may not be superseded by something yet more effective after a short time. Summary.

1. Following on a test of diasone in the treatment of 83 patients in the West Indies, which was previously reported on, the author made a further test in twelve patients.

2. The method of administration is described; the dosage is carefully regulated till a maximum of 12 grammes a week for 3 weeks in the month is reached.

3. Details of the treatment and results in each case are given.

4. Beneficial results were obtained in all cases, though it is still too early to estimate the full and final results.

Muir, E. (1944) Preliminary Report on Diasone in the Treatment of Leprosy, Int. Jl. Lep., 12, 1.

Smith, M. I., Emmart, E. W., and Stohlman, E. F. (1943), The Action of some Derivatives of 4-4'-Diaminodiphenylsulfone in Experimental Tuberculosis. Amer. Rev. Tuberculosis, 48, 32. 